\title{
Minhas mães, meus pais, minhas tias e meus tios: a teoria do parentesco como contribuição ao estudo das formas de tratamento nominais de Angola e de Moçambique
}

\author{
Sabrina Rodrigues Garcia Balsalobre \\ Universidade Estadual Paulista "Júlio de Mesquita Filho" (UNESP), \\ Araraquara, São Paulo, Brasil \\ sabrinabalsalobre@yahoo.com.br
}

DOI: http://dx.doi.org/10.21165/el.v46i1.1542

\begin{abstract}
Resumo
Neste estudo, propõe-se estabelecer um vínculo teórico entre o sistema de parentesco contribuição da antropologia - e a perspectiva sociopragmática de estudos linguísticos, na medida em que ambas se preocupam com a eficiência da comunicação humana ao observarem a existência de regras culturais que regem os relacionamentos interpessoais. Assim sendo, o objetivo principal é observar a associação entre as formas de tratamento nominais utilizadas por falantes angolanos e moçambicanos à nomenclatura classificatória do parentesco, uma vez que uma mesma forma pode designar diferentes pessoas, aplicando-se a uma vasta gama de relações.
\end{abstract}

Palavras-chave: teoria do parentesco; sociopragmática; sistema de formas de tratamento nominais.

My mothers, my fathers, my aunts, my uncles: the kinship theory as a contribution to the study of nominal Angola and Mozambique addressing forms

\begin{abstract}
This study proposes to establish a theoretical link between the kinship system - an anthropology contribution - and sociopragmatic perspective of linguistic studies, in that both are concerned with the efficiency of human communication to observe the existence of cultural rules governing interpersonal relationships. Therefore, the main objective is to observe the association between the nominal addressing forms used by Angolan and Mozambican speakers to the classification nomenclature of kinship, since the same form can assign different people, applying to a wide range of relationships.
\end{abstract}

Keywords: kinship theory; sociopragmatic; nominal addressing system.

\section{Introdução}

Toda sociedade humana organiza-se em torno de experiências sociais e, para isso, usa itens lexicais de seus idiomas para expressar a natureza desses contatos. À antropologia coube a tarefa de observar e interpretar essas formas de convívio por meio da Teoria do Parentesco (LÉVI-STRAUSS, 1982, 1993; RADCLIFFE-BROWN, 1969, 1974). Nesse sentido, o estudo das formas de tratamento apresenta uma imbricação direta com essa teoria, já que esse recurso do sistema linguístico representa a maneira como as comunidades expressam esses arranjos sociais. Fundamental, portanto, é estabelecer um vínculo teórico entre as relações de parentesco e a perspectiva sociopragmática, na medida em que ambas preocupam-se com a eficiência da 
comunicação humana ao observarem a existência de regras culturais que regem os relacionamentos interpessoais.

As formas de tratamento foram privilegiadas, enquanto objeto linguístico de análise neste estudo, em decorrência de representarem um elemento do sistema linguístico que favorece diretamente a análise da correlação entre a língua e seus correspondentes sociais. Esse ponto configura o pressuposto fundamental deste trabalho investigativo: língua e sociedade devem ser analisadas conjuntamente em função de sua inter-relação. Com esse propósito, observaram-se as formas de tratamento nominais utilizadas por falantes de dois países pertencentes aos PALOP (Países Africanos de Língua Oficial Portuguesa), a saber: Angola (mais especificamente a variedade utilizada em sua capital Luanda) e Moçambique (igualmente, a variedade utilizada na capital Maputo).

Angola é um país situado na África Ocidental, portanto, semelhantemente ao Brasil, é banhado pelo Oceano Atlântico. Sua população é estimada em 21,47 milhões de habitantes (dado de 2013), sendo que boa parte desse total está em idade economicamente ativa, impulsionando o desenvolvimento do país. Segundo os pesquisadores do Relatório Social de Angola 2012 (RSA, 2012, p. 38), no país,

[...] o fenômeno da urbanização tem sido muito intenso nos últimos anos, fazendo de Luanda a grande metrópole de Angola, com uma população estimada em mais de 6,5 milhões de habitantes e exercendo um efeito de atracção notável que a transforma no principal e mais importante polo de crescimento económico do país.

Nesse sentido, a previsão é que para 2020 a taxa de concentração urbana poderá chegar a $72 \%$.

Em termos linguísticos, nota-se que $82,8 \%$ dos angolanos falam português, dividindo o cenário com outras línguas autóctones, como o umbundo - utilizado por $28,7 \%$ da população -, o quimbundo $(9,5 \%)$ e o kikongo $(8,7 \%)$, de acordo com dados do Inquérito do Bem-estar da População (IBEP), realizado pelo Instituto Nacional de Estatística (INE), em 2011. Nesse sentido, Luanda conta com uma maioria de pessoas que têm como língua materna o português, em função do prestígio social que essa língua paulatinamente vai adquirindo. Nos espaços urbanos, portanto, a comunicação é realizada principalmente em língua portuguesa, associando as línguas autóctones aos espaços religiosos e 'familiares tradicionais' - ou seja, na maioria das famílias luandenses, a interlocução se dá em português e o uso das línguas tipicamente angolanas ocorre em visitas a familiares mais velhos e/ou residentes em outras províncias.

Por sua vez, Moçambique é um país situado ao sul do Continente Africano, banhado pelas águas do Oceano Índico, com uma população de 25.830 milhões de habitantes (segundo estimativa de 2013), sendo que 5,4\% desse montante se encontra residindo na capital Maputo. Nesse contexto, de acordo com o censo de 2007, a língua portuguesa - falada por $42,9 \%$ da população - divide o cenário linguístico com, principalmente, cinco outras línguas nacionais, destacando-se a Xichangana, utilizada por $31,5 \%$ dos falantes de Maputo.

Ao se considerar esse ambiente linguístico da capital de Moçambique, Maputo, é possível estabelecer um panorama sobre os papéis sócio-simbólicos desempenhados pelas diferentes línguas. A cidade de Maputo é, em linhas gerais, dividida por três zonas 
(FIRMINO, 2006): zona central, onde se concentram os negócios, comércio, circulação de estrangeiros ocupados com empresas e ONGs etc.; zona intermédia, predominantemente residencial, com estabelecimentos comerciais de menor porte e comércio informal; e zona rural, onde residem e trabalham pequenos agricultores em suas machambas ${ }^{1}$. Com esse cenário delineado, Firmino (2006) aponta que o uso das línguas autóctones moçambicanas representa a forma de comunicação primária das zonas rurais - esse fato coaduna com os dados do Censo de 2007 apresentados acima, em que apenas $36,6 \%$ de habitantes da zona rural falam português. Já em zonas suburbanas - mais afastadas da região central - ocorre também o uso de línguas autóctones, mas com algumas ocasiões em que o português é escolhido em função das necessidades comunicacionais. Nas regiões intermédias, há uma presença importante de situação de interlocução em línguas nacionais - na cidade de Maputo, majoritariamente no idioma Xichangana. Entretanto, Firmino (2006, p. 87) alerta para o fato de que, mesmo nessas regiões, é ascendente o prestígio do português, haja vista "os pais fazerem esforços para criar os filhos em Português". Essa situação se evidencia nas famílias cujos pais possuem um bom domínio do português. Dessa forma, o autor aponta para o fato de que, mesmo nessas regiões intermédias, já há uma geração de crianças que falam o português como língua materna (42,9\%, conforme dados do Censo 2007). Por fim, a tendência primordial da zona central é a comunicação se realizar em língua portuguesa, com pouca presença de línguas locais. Nesse sentido,

[...] a diferença é que o uso de línguas autóctones na zona central é regressivo, enquanto o uso do Português na zona intermédia é progressivo, especialmente entre pessoas escolarizadas, como consequência do prestígio social que é concedido ao Português, não apenas na zona central, mas também na intermédia. (FIRMINO, 2006, p. 88).

Entre moçambicanos e angolanos há um item linguístico em comum, no sistema de formas de tratamento, que amplamente caracteriza esses dois povos e que é o objeto principal de análise do presente estudo: o uso de formas de tratamento familiares ${ }^{2}$ termo aqui adotado para expressar o fenômeno em análise. Cotidianamente, nas ruas da cidade de Maputo e de Luanda, ouvem-se diálogos em que os interlocutores, ainda que desconhecidos, tratam-se por meio de formas que, ocidentalmente, são empregadas para a referência alocutiva e delocutiva de membros da família consanguínea, tais como "mãe", "mamãe", "pai", "papai", "avô(ó)", "mano(a"), "tio(a)", "titio(a)", "madrinha", "padrinho" etc. Tanto os informantes de Moçambique, quanto os de Angola, forneceram

\footnotetext{
${ }^{1}$ Machamba significa 'horta' em português.

${ }^{2}$ É preciso reconhecer que o uso de FTNs familiares para pessoas desconhecidas não se restringe apenas aos contextos culturais moçambicano e angolano, mas é prática comum em diversas comunidades africanas. Para ilustrar esse fato, segue um excerto do romance nigeriano Americanah (2014), de Chimamanda Ngozi Adichie - com tradução de Julia Rumeu, publicado pela Companhia das Letras ambientado em Lagos, Nigéria. Nessa passagem, a protagonista Ifemelu, depois de um longo período morando nos Estados Unidos, volta a Lagos e aluga uma casa que precisa ser reformada. No diálogo a seguir, ela conversa com um dos operários responsáveis pela reforma:

“"Que maluquice é essa? Olhe só como isso está áspero! Um dos azulejos está quebrado! Está pior que os azulejos velhos! Como você pode considerar um trabalho acabado?', ela perguntou ao homem.

Ele deu de ombros; claramente, achava que ela estava dificultando as coisas de forma desnecessária. 'Estou feliz com o trabalho, tia.'

'E quer que eu pague?'

Um pequeno sorriso. "Ah, tia, mas eu terminei o trabalho"” (ADICHIE, 2014, p. 425).
} 
diversos exemplos que ilustram esse tipo de tratamento ${ }^{3}$. Assim, seguem os excertos ilustrativos:

(01) “Aqui seria a mesma coisa que a, que a... bom dia, papá. Bom dia, papá. Aqui é... papá sabe onde está a Laurinda? Papá sabe onde vive a Laurinda? Papá viu a Laurinda?” (MO, Mulher, 50 anos, Superior Completo, gestora $)^{4}$

(02) "Eu tô, vovô, eu tô a perguntar onde vive Laurinda. Ele vai dizer: conheço onde tá viver Laurinda." (MO, Homem, 14 anos, $7^{\mathrm{a}}$ classe, estudante, rhonga)

(03) "Este senhor: boa tarde, tio ou pai também. Boa tarde, tio. Eu tô à procura da dona Amélia. Será que o tio conhece ela? Pode indicar-me onde ela vive? E muito obrigada... seria primeiro por favor. Sim, pedir favor. E depois de tudo muito obrigada.” (AN, Mulher, 19 anos, Superior incompleto - em andamento, bibliotecária)

(04) "Boa tarde, mamá. Mamá, desculpa. Por aqui assim não há uma cantina próxima onde eu posso comprar um quilo de farinha, um quilito de arroz?" (AN, Homem, 49 anos, Ensino Primário, segurança, ngoia)

Com o objeto de estudo apresentado, faz-se, então, necessário apresentar os fundamentos teórico-metodológicos que subsidiaram essa análise e que, decisivamente, contribuíram para a compreensão desse item do sistema de formas de tratamento, que estritamente relaciona os usos linguísticos aos seus motivadores sociais.

\section{Formas de tratamento nominais}

Com o objetivo de se analisar as relações entre a língua portuguesa e suas representações sociais - mais especificamente perscrutando as sociedades moçambicana e angolana - optou-se por privilegiar um recurso do sistema linguístico que expressa a inter-relação entre escolhas linguísticas e motivadores sociais. Com esse propósito, o sistema de formas de tratamento nominais (doravante FTN) é o fenômeno linguístico investigado por esse estudo.

Uma vez que está em foco a investigação da língua e de seus motivadores sociais, a abordagem que fundamenta essa análise é a Sociolinguística - que apresenta a característica fundamental de ser uma ciência interdisciplinar. De acordo com essa concepção, a língua constitui-se um sistema complexo e heterogêneo, passível de sofrer variação e mudança. Dessa forma, segundo o viés sociolinguístico, as escolhas linguísticas correspondem às características sociais dos falantes - portanto, a variação nas formas de tratamento é motivada pelas variáveis sociais. Além dessa abordagem, complementarmente também está em foco um olhar pragmático aos dados. A intenção é observar as razões que levam os falantes a empregar determinadas formas em determinados contextos. Em outras palavras, a partir do viés pragmático, é possível compreender os efeitos de sentido gerados com as escolhas tratamentais feitas pelos falantes em interação.

3 Em seção subsequente, mais especificamente a denominada "Metodologia de pesquisa", os procedimentos de entrevista aos falantes angolanos e moçambicanos serão mais detidamente focados a fim de se aclarar a forma como esses enunciados foram produzidos.

4 Após os excertos dos entrevistados, serão oferecidas informações a respeito dos entrevistados, salvaguardando as suas identidades. Dessa forma, entre parênteses, haverá a indicação do país (MO para Moçambique e AN para Angola), o sexo, a idade, o nível de escolaridade, a profissão e, apenas para os que autodeclararam, a etnia. 
Em termos gerais, as formas de tratamento são palavras ou sintagmas usados por falantes de uma língua a fim de se dirigir ou de se referir a outra pessoa. Com propósitos didáticos, esse sistema pode ser subdivido em dois macro níveis: i) formas pronominais: palavras ou expressões equivalentes aos pronomes de tratamento (você, tu, o senhor, a senhora etc.); ii) Formas nominais - privilegiadas por esse estudo: expressões provenientes de substantivos comuns, nomes próprios, termos de parentesco, profissões etc. São exemplos: amiga, querida, cara, primo, doutor, irmão, chuchu etc.

Uma vez que os termos de endereçamento abrangem as diversas possibilidades disponíveis na língua para que um falante se dirija ou se refira a alguém, esse fenômeno linguístico é constituído em seu âmago por um código social. Nesse aspecto, segundo Causse-Cathcart (2011), o estudo das formas de tratamento permite que se conheça o funcionamento de uma sociedade, uma vez que ele demonstra as formas como estão estabelecidas as relações sociais. Na mesma linha de raciocínio, Acevedo (2011) entende que os usos tratamentais são socialmente fixados e, ao empregarem-nos, os falantes ativam seus esquemas mentais e manejam os valores atribuídos aos interlocutores. Portanto, "o emprego do tratamento não depende propriamente do sistema linguístico, mas depende da forma como a sociedade está organizada" (SILVA, 2008, p. 61).

Ao se considerar que as sociedades possuem divisões hierárquicas, cada membro que compõe esse todo social desempenha um papel para esse grupo e, por suas características mais contundentes, passa a ser reconhecido - idade, sexo, posição familiar, hierarquia social, grau de intimidade etc. De acordo com Silva (2011), as formas de tratamento mobilizadas na interação levam em consideração as posições que cada um dos participantes desempenha na escala social. Quando esse pressuposto comunicacional não é seguido a contento, ocorrem sérias consequências ao sucesso da interação. Apesar disso, desde que se reconheça o princípio de que a língua e a sociedade são sistemas dinâmicos, o mesmo é preciso considerar com relação às formas de tratamento. Assim, uma vez que a sociedade está sujeita a alterações ao longo de sua história, as formas de tratamento também mudam. É preciso considerar, portanto, que o sistema de tratamentos é a expressão linguística da estrutura social vigente em determinado momento histórico (SILVA, 2011).

Intentando sintetizar a interação entre os fatores sociais e linguísticos para o estudo das formas de tratamento, Lopes et al. (2011, p. 315-316) concluem:

Em outras palavras, existiria um sistema de regras de interação social que condiciona o uso das formas de tratamento de acordo com o papel social dos interlocutores envolvidos na cena comunicativa que pode ser mais ou menos consciente por parte do falante. Além disso, há de se considerar que as convenções sociais, principalmente as relacionadas ao tratamento, se configuram linguisticamente de maneira integrativa, uma vez que as normas sociais se consubstancializam em normas linguísticas. Isso quer dizer que não só se levam em consideração as regras sociais que determinam os usos tratamentais, mas também devem ser observados os fatores linguísticos que podem condicionar o emprego de uma ou outra forma de tratamento. Os dois caminhos precisam convergir na explicação do processo de mudança no sistema de tratamento do português.

À busca de aprofundar a compreensão do componente social das formas de tratamento, faz-se imprescindível analisá-las pelo viés da interação. Com esse propósito, 
o primeiro pressuposto a se considerar é o fato de que os tratamentos representam ao falante o primeiro recurso de que dispõe para "marcar e construir a relação interpessoal" (KEBRAT-ORECCHIONI, 2011, p. 19.). Nesse sentido, Kebrat-Orecchioni (2011, p. 19) atribui às formas de tratamento a alcunha de "poderosos relacionemas", já que sua função primordial é relacionar as pessoas no discurso.

Pelo fato de que as FTNs podem expressar tanto índices de cortesia, consideração, simpatia, quanto de agressão, hostilidade, aborrecimento, elas representam fundamentalmente um caráter ambivalente (ora afetuoso e positivo, ora negativo e brutal). Nesse sentido, arrola-se mais uma função das FTNs: a de veicular uma carga emocional por meio das escolhas disponibilizadas pelo sistema. Assim:

A tarefa do analista consiste, portanto, em tentar desfazer o emaranhado de fatores que intervêm na gênese desses efeitos opostos, no discurso, e que dependem tanto do tipo de FTN quanto dos diversos elementos que compõem o contexto externo e interno - tais como seu posicionamento na interação, no turno de fala, ou no enunciado; o seu acompanhamento prosódico ou mimo-gestual; bem como o tipo de ato ilocutório e perlocutório que as FTN acompanham. (KEBRAT-ORECCHIONI, 2011, p. 37).

\section{Teoria do parentesco}

Para compreender o fenômeno linguístico em discussão, as formas de tratamento nominais, particularmente, as formas de tratamento familiares, fecunda contribuição foi oferecida pela antropologia, por meio da teoria do parentesco - que propiciou um produtivo olhar sobre as formas de tratamento em sua intersecção entre o linguístico e o social/cultural.

Quando se vive imerso em uma única cultura - sem conjecturar a existência de outros povos, com outras organizações sociais -, cria-se a falsa ideia de que a concepção de "família" constitui-se em algo universal e natural. Sobretudo, é tendência naturalizar o conceito de família a que se está submerso como o único possível e verdadeiro. Entretanto, cada agrupamento humano pode estabelecer uma coerência interna para se socializar. Em função dessas divergentes formas de se conceber "família", há estudos antropológicos dedicados ao "parentesco". Trata-se, pois, da teoria do parentesco. Pesquisadores como Lévi-Strauss (1982) e Radcliffe-Brown (1969, 1974), ao analisarem sociedades demograficamente menores e tradicionais, observaram que as relações de parentesco preveem imbricações de outras naturezas, como as econômicas, religiosas e políticas. Nesse sentido, os sistemas parentais são partes integrantes da estrutura de uma sociedade, por formarem redes de relações sociais. Em outras palavras: "o sistema de parentesco é por isso uma teia de relações sociais que constitui parte da rede total das relações que é a estrutura social" (RADCLIFFE-BROWN, 1974, p. 25).

Em termos gerais, família é um conceito elementar que congrega indivíduos que, entre si, estabelecem um convívio. Lévi-Strauss (1982, p. 523) é assaz contundente quando se refere à importância dos laços sociais para as sociedades humanas:

Uma relação não pode ser isolada arbitrariamente de todas as outras, e também não é possível que o indivíduo se mantenha aquém ou além do mundo das relações. O meio social não deve ser concebido com um quadro vazio no interior do qual os seres e as 
coisas podem ser ligados, ou simplesmente justapostos. O meio é inseparável das coisas que nele habitam.

Há diferentes tipos de agrupamentos familiares e o mais comum é o que se designa por "família conjugal", “em que o agregado é constituído pelos pais e os seus filhos menores ou solteiros" (RADCLIFFE-BROWN, 1974, p. 16). Ao se tomar como referência um único indivíduo, todos os seus parentes são classificados em relação a ele. Assim sendo, para estabelecer esses tipos de relações parentais, mais especificamente para classificar os parentes de uma pessoa, postulou-se um sistema de parentesco com uma nomenclatura específica. De acordo com Radcliffe-Brown (1974, p. 38): "Nós damos um mesmo nome a um certo número de coisas quando pensamos que elas são semelhantes em alguma característica importante. Assim usamos em inglês o mesmo nome - tio - para irmão da mãe e irmão do pai porque pensamos que são semelhantes, como parentes da mesma espécie".

Marie (1978) afirma que o parentesco não necessariamente é uma condição biológica e consanguínea, mas, sim, uma relação social. Segundo a autora, a noção de "filiação" pode ser "mítica", no sentido de que existe apenas na consciência dos homens, ao exprimir um tipo de relacionamento afetivo. Ao se considerar a não obrigatoriedade dos laços consanguíneos, a expressão das condições de parentesco por meio das formas de tratamento ganha uma dimensão muito mais extensa, que em grande medida auxilia na explicação dos dados empíricos fornecidos pelos informantes dessa pesquisa. Nesse aspecto, ganha suma relevância a seguinte afirmação de Marie (1978, p. 20):

Numa palavra, o parentesco não é apenas um princípio de classificação e de organização, é também um código, uma linguagem mais ou menos ideológica e mais ou menos manipulada. É, pois, uma chave para a interpretação de todas as sociedades (mesmo as sociedades com Estado) em que o parentesco não se reduz à família conjugal, mas preside, totalmente ou em parte, à formação de grupos sociais e à organização das relações entre os mesmos. Mas é uma chave que convém manejar com precaução: considerando as suas múltiplas possibilidades e não esquecendo, em particular, que a linguagem do parentesco pode mentir. É preciso, portanto, confrontar de cada vez o estudo do parentesco com a análise das situações concretas nas quais o parentesco (o seu vocabulário, bem como as atitudes mais ou menos convencionais que prescreve) está implicado.

Em termos gerais, a nomenclatura do parentesco prevê duas macrodivisões: o sistema descritivo e o classificatório. Na concepção de Marie (1978, p. 54), o sistema descritivo estabelece "um reduzido número de termos específicos para os parentes do primeiro ou do segundo grau e outros parentes mais afastados são designados por palavras compostas destes termos" (MARIE, 1978, p. 54). Esse sistema descreve, sobretudo, as sociedades ocidentais majoritárias, em que uma pessoa possuirá apenas um pai, uma mãe, um sogro, uma nora, tios e tias em função da quantidade de irmãos da mãe e do pai etc.

Já no sistema classificatório, que descreve fundamentalmente sociedades tradicionais, como as ameríndias e as africanas, um único termo é empregado para designar um conjunto de pessoas, aplicando-se a uma vasta gama de relações. "Por este processo de extensão do princípio de classificação, os parentes colaterais mais próximos e mais distantes são agrupados em poucas categorias e a pessoa tem muitos parentes a 
quem se aplica o termo 'pai' ou 'mãe' ou 'irmão' ou 'irmã'” (RADCLIFFE-BROWN, 1974, p. 20). Nesse sentido, por exemplo, todos os parentes da geração do "pai" e da "mãe" podem ser denominados também como "pai" e "mãe". E, ao agir dessa forma, subjaz a ideia de que todos estes parentes pertencem a uma mesma espécie geral.

As sociedades que adotam a terminologia classificatória contam com sistemas familiares extensos. Nesses casos, está previsto que um dado comportamento seja padronizado como apropriado para todos os membros familiares que receberem uma mesma designação. "Em certos exemplos, o padrão pode ser definido por referência a direitos e deveres específicos ou modos determinados de comportamento" (RADCLIFFE-BROWN, 1969, p. 78-79).

Nesse sentido, o estudo das formas de tratamento apresenta uma imbricação direta com essa teoria, já que esse recurso do sistema linguístico representa a maneira como as comunidades expressam esses arranjos sociais. A partir dos exemplos de formas de tratamento familiares expressos (cf. excertos de 01 a 04), que correspondem a usos moçambicanos e angolanos, é possível associá-los à nomenclatura classificatória do parentesco, uma vez que uma mesma forma pode designar diferentes pessoas. A fim de clarificar essa afirmação, ao se tomar o exemplo da FTN "mãe”, é observável que, em contexto africano, ela não designa apenas a progenitora de alguém, mas todas as pessoas que poderiam ocupar simbolicamente esse papel.

Quando os pesquisadores da teoria do parentesco empregam a nomenclatura classificatória, normalmente, intenta-se referir a agrupamentos familiares extensos, em que muitas pessoas podem desempenhar a função de "pai" para um indivíduo tomado como ponto de referência. Todavia, os informantes moçambicanos e angolanos que participaram como informantes da presente investigação referiram-se ao fato de que usam as FTNs familiares para pessoas desconhecidas com quem estabelecem um primeiro contato, seja nas ruas, seja em instituições comerciais e administrativas. Nesse sentido, ao utilizar o termo classificatório, na pesquisa ora em discussão, está em voga a sua acepção mais extensiva, haja vista que "mãe", por exemplo, pode ser um termo destinado a todas as mulheres de um dado contexto social que possam desempenhar a simbólica função de "mãe" para um sujeito informante - com a importante ressalva de que essa extensão conta com algumas restrições, sobretudo de ordem identitária, conforme será debatido nas seções subsequentes.

\section{Metodologia de pesquisa}

A fim de se levar a cabo a investigação das formas de tratamento nominais das variedades angolana e moçambicana da língua portuguesa, foram entrevistados 25 angolanos, residentes na cidade de Luanda, e 25 moçambicanos da cidade de Maputo, durante os meses de janeiro a junho de 2013.

É notória a dificuldade enfrentada por pesquisadores de formas de tratamento para captar usos linguísticos reais, pois, ao se realizar uma entrevista sociolinguística típica, os tratamentos entre entrevistador e entrevistado se repetem e não são produzidos em abundância pelos interlocutores, uma vez que os papéis sociais e os níveis de formalidade tendem a permanecer estáveis durante o período da gravação. Sendo assim, optou-se pelo emprego de um método bastante utilizado nos anos 1980, que consistia no 
emprego de fotografias como recurso motivador de interação ${ }^{5}$. Dessa forma, 20 imagens de pessoas foram apresentadas aos informantes dos dois países. Em um primeiro momento, fornecia-se a instrução ao informante de que todas as pessoas fotografadas eram para ele desconhecidas e que as encontraria na rua, em estabelecimentos comerciais ou instituições públicas. A proposta feita aos entrevistados era que a pesquisadora indicaria, para cada imagem, uma instrução específica contendo um pedido acerca de endereço, referência acerca de uma pessoa que se está procurando, o preço de determinado produto etc. Tendo compreendido a instrução, o informante estabelecia um diálogo com a pessoa da fotografia.

Em geral, a grande maioria dos informantes compreendia prontamente a proposta da entrevista e produzia naturalmente diversas formas de tratamento. Em determinados momentos, a pesquisadora intervinha pedindo para que o informante justificasse algum uso que causasse dúvida ou propunha outra situação a fim de confirmar a estratégia de endereçamento por ele empregada.

\section{FTNs familiares para desconhecidos}

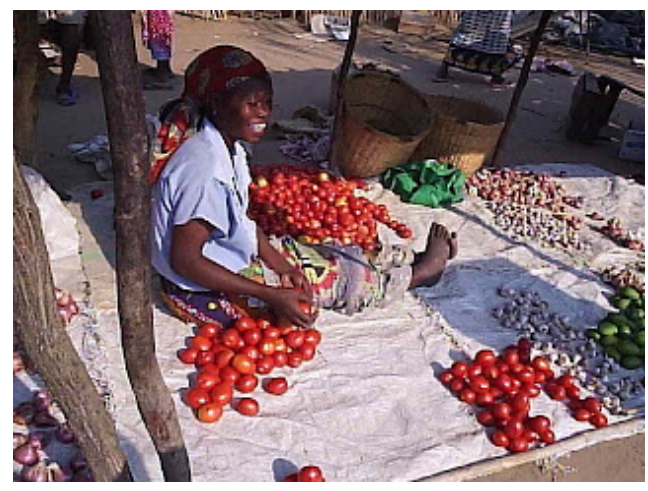

Figura 1. Perfil da amostra moçambicana ${ }^{6}$

Ao ser apresentada a Figura 1 a um informante moçambicano, ele simulou o seguinte diálogo:

(05) "Eu diria: boa tarde, mãe. Quanto custa este molho, este molho de tomate? Então, ela ia, ela ia dizer o preço do tomate. Então, se pudesse comprar eu iria comprar. Exato. Por que chamaria de mãe? É, por uma coisa muito simples. Eu gosto da minha mãe. Então, para todas as pessoas que têm a idade, poderia não ser velho, mas que eu vejo e, e, e, e percebo que ela é mãe, então, eu tenho esse tratamento também. Mas não seria minha mãe. Mas talvez aquelas pessoas mais velhas que têm a idade da minha mãe, né . Exato. Costumo chamá-las de mãe." (MO, Homem, 24 anos, Curso técnico de Hotelaria e turismo - em andamento, pintor de residências, tonga)

De modo geral, os informantes moçambicanos e angolanos justificaram-se de forma bastante semelhante quanto às motivações que os levam a abordar desconhecidos por meio dos tratamentos familiares. Nesse sentido, uma razão que se destaca é que, ao

\footnotetext{
${ }^{5}$ Para mais informações sobre a metodologia que utiliza imagens para o estudo das formas de tratamento, cf.: BALSALOBRE, S. R. G. Fotografias como estratégia metodológica: perscrutando formas de tratamento pronominais brasileiras, moçambicanas e angolanas. LaborHistórico, Rio de Janeiro, 1 (1), p. 132-148, jan./jun. 2015.

${ }^{6}$ Disponível em: <http://olhosdeleoa.blogspot.com/2009_07_01_archive.html>. Acesso em: 11 fev. 2013.

${ }^{7}$ Grifos meus.
} 
abordar alguém por meio do emprego de "mãe", por exemplo, atribuem-se o mesmo respeito e carinho que se atribuiria a sua própria mãe à pessoa interpelada.

Esses depoimentos dos informantes que contêm justificativas para o emprego cotidiano de FTNs familiares para pessoas que não pertencem legitimamente à sua família, corrobora com a proposição de Radcliffe-Brown (1974), segundo a qual, para se compreender mais profundamente as relações parentais que se estabelecem em dada comunidade, é preciso considerar elementos de naturezas distintas. Nesse sentido, o autor afirma que há elementos afetivos - ou seja, relações tipicamente sentimentais permeando determinadas relações. "Assim podemos dizer que na generalidade das sociedades humanas uma forte afeição mútua é a característica normal da relação entre mãe e filho, ou pode existir em determinada sociedade uma atitude emocional normal ou típica do filho em relação ao seu pai” (RADCLIFFE-BROWN, 1974, p. 23).

Alguns informantes - tanto moçambicanos quanto angolanos - simularam uma situação de interlocução completa, ou seja, produziram um diálogo em que aparecia a FTN que dirigiriam a um determinado perfil e a resposta hipotética que receberiam dessa pessoa. Alguns desses casos serão aqui reproduzidos a fim de que se observe a forma como se estabelecem as interações nessas duas sociedades - ainda que não se trate de diálogos autênticos, nessa pesquisa leva-se em consideração o conhecimento de mundo desses informantes:

(06) "Depois chego lá, atravesso e pergunto: desculpa lá, este chapa pra onde é que vai? Né? A gente saúda, dependendo da hora: bom dia, este chapa vai pra onde? Ah, vai pra Elisa, vai pra Chalé, vai pra Catembe, vai pra Ponta D’Ouro, vai pra Bela Vista. Então, qual é que posso apanhar? Apanha ali aquele. Pronto, é naquele que eu vou.

(Pronto. Então, pra ela seria essa pergunta, né?)

Sim, sim. E ela, ó, ela como tá aqui na ponte, ela diria assim: minha filha, atravessa, lá tem chapas pra todo lado, não é? Minha filha, este chapa vai pra não sei onde. Eu não me preocupo com isso. E eu também não, não me preocupo em dizer: obrigada, mãe." (MO, mulher, 43 anos, Ensino Secundário Incompleto, dona de casa, rhonga)

(07) "Não estou numa zona, numa zona, urbanização. Então, quer dizer, na cidade. Então, quando eu for tratar com ele, também vou-lhe tratar com muito mais respeito. Com muito mais costume. E vou chegar lá: ah, pai, boa tarde, boa noite. Ah, boa tarde, minha filha. Sempre a resposta vai ser essa. [...] Quando tu vais e tratas ele como pai, ele automaticamente já vai te tratar: ah, boa tarde, minha filha. Ai, como está? Tá tudo bem? Ai, então, e aqui a zona? Eh pá, vai reclamar. Normalmente nas zonas rurais tu tens de dar muito mais conversa.

(Ah é?)

Porque eles gostam. Ah, então, como está? Ah, seca. Ih, a chuva. Ah, não tivemos muito milho este ano. Ah, mas não se preocupa, pai, vai ficar tudo bem. Ah, sim, sim, vão tá tudo bem. Mas as crianças em casa tá tudo bem? Ah, é, sim, mas eh pá, há fome, minha filha. Há fome. É? Hum, hum. Sabe, pai? Hum. Eu tô a procura da casa da dona Laurinda. Num tô a encontrar. Ah, dona Laurinda é ali ali ali. Ali? Sim. Aqui perto, aqui. Aqui perto aqui ou aqui perto lá? Aqui perto, aqui, aqui. Ah, ok. Ah, mas vamos, vou te acompanhar." (MO, mulher, 27 anos, Ensino Superior em Ciências Políticas, Corretora de seguros)

(08) “Ô mano. Elas às vezes chamam mesmo mano. Mano, peixe, queres comprar? Tá com... é até a forma de chamar às vezes, né. Umas chamam mano. Um termo que é muito... papá.

(Papá?)

Papá. E aí você vai. Quanto é? Ah, é (?). Ah não, é muito caro. Tá a ver? É mesmo assim. É muito caro, não. E você olha pra qualidade e começa a olhar nos outros porque geralmente elas não ficam isoladas. 
Aí eu vou lá. (?) Tudo bem, mamá? Quanto é esse, quanto é isso? É X. Ê, mas abaixa mais um pouco. É caro. Ih, papá, eu também comprei caro.

(Isso.)

Ah, mamá, tás a vender caro pra mim. Um começa papá, outro mamá. Papá, mamá. E a coisa vai indo assim." (AN, Homem, 56 anos, Graduou-se em Filosofia e Teologia no Seminário, gestor de serviços gerais de uma universidade, bakongo)

(09) "Então, eu, eu chegaria... bom, ele eu diria que é avô. Pela idade, já com cabelo branco eu chegaria e assim: Boa tarde, avô. Sim, boa tarde, minha filha. Ah, eu estou à procura da Amélia. Por acaso, o pai conhece a casa dela? Sei que ela vive aqui nos arredores. Amélia? Ah, sim, Amélia fica lá. A casa é aquela mesmo." (AN, Mulher, 23 anos, Curso superior em Economia em andamento, bibliotecária, quimbundo)

Essas simulações de diálogos trazem à tona o fato de que, para se estabelecer o sistema de parentesco de uma dada comunidade, classificam-se todos os parentes de um indivíduo tomado com referencial e, a partir disso, "é possível formular certos princípios gerais quanto ao seu comportamento para com as pessoas pertencentes a diferentes gerações" (RADCLIFFE-BROWN, 1974, p. 42). Nesse sentido, quando os informantes afirmam saberem a forma como seriam correspondidos por seus interlocutores, isso se dá em função de terem introjetado esses princípios gerais, a que se refere Radcliffe-Brown, e que regem as situações interlocutivas. Além disso, Marie (1978) pontua que, para se estabelecer o sistema de denominações de uma dada cultura, é necessário considerar o fato de que as formas utilizadas para se dirigir ou se referir a alguém implicam uma "correlação ou uma reciprocidade; assim, pai implica filho e vice-versa” (MARIE, 1978, p. 54).

Conforme expresso, para além da questão do carinho e do respeito, outra justificativa muito produtiva oferecida pelos informantes - sobretudo por angolanos para a utilização de tratamentos familiares para desconhecidos se refere a questões de identidade. A fim de expressar o sentimento de pertença cultural, os informantes se auto-afirmaram "angolanos", "bakongos", "umbundos", "africanos", "bantu" etc. por se reconhecerem como pertencentes ao mesmo contexto do que os perfis a eles apresentados. Essas questões de pertencimento identitário são assim expressas pelos informantes:

(10) "Porque essa história de mãe, pai, tio, a gente traz do, do, do nosso bairro. Lá do bairro onde nós convivemos. Então, crescemos com aquilo". (MO, mulher, 57 anos, Superior Incompleto, artesã, changana)

(11) “(Por quê? Que que motiva?) O que que motiva, é, bom, na nossa cultura, na minha cultura, na cultura umbundo, mesmo na cultura bantu de uma forma geral, portanto, os mais velhos ocupam um lugar de muita respeitabilidade no seio da comunidade. E, então, todo o indivíduo que aparente ter a idade de alguém que podia ser meu pai eu trato como um pai, como paizinho, como pai, papá, paizinho.” (AN, homem, 60 anos, Superior Completo, professor universitário, umbundo)

(12) "Normalmente, nós bakongo temos nossa, temos a nossa particularidade de chegar até alguém, por exemplo, se for uma mamá como essa... essa mamá, pelo que ela vestiu, pelos panos que ela tá a usar, dá pra ver que ela é bakongo.

(É sério?)

Sim. Essa mamá, os panos que ela tá a usar, ela é bakongo. Então, ao chegar a uma bakongo, né, ao chegar a uma bakongo, eu não chamo tia. Se for senhora, eu tenho que chamar mamá, porque ela é como a minha mãe. Hum. Então, eu chego: mamá, quanto é que é? É mamá mesmo." (AN, mulher, 30 anos, Curso Superior de Economia - em andamento, bibliotecária, bakongo) 
Entretanto, em função de algumas reações dos entrevistados, ficou evidente que o uso de formas de tratamento familiares conta com algumas restrições, sobretudo de ordem identitária. Assim sendo, quando exposta à Figura 2, uma moçambicana produziu o seguinte diálogo:

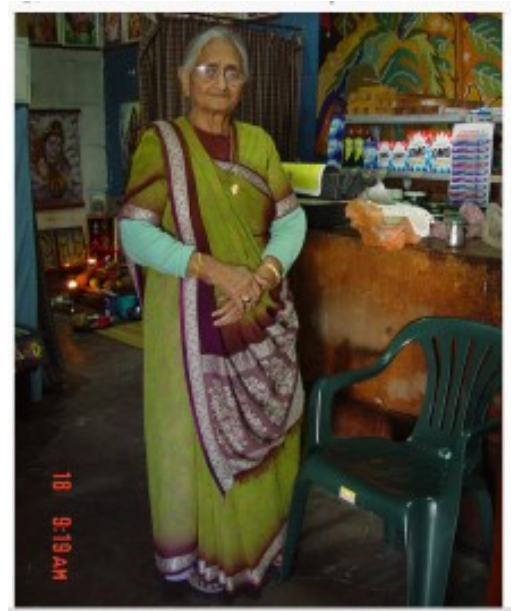

Figura 2. Perfil da amostra moçambicana ${ }^{8}$

(13) "Eu ia dizer: boa tarde, senhora. Podia me dizer o preço do Omo, quanto é que tá?

(Você chamou de senhora. No entanto, a gente percebe que ela tem os cabelos brancos, tudo. Vovó?)

Mas ela não é negra. Então, ela não ia gostar de vovó.

(Pra ela não cabe?)

Não. Ela havia de dizer: eu não sou vovó. Não, ela não havia de gostar.

(Pra ela só senhora pode ser ou teria outro?)

Senhora só. Eu não sei como é que eu haveria de me, de me dirigir a ela.

(Tá.) (?). Senhora é a melhor maneira." (MO, mulher, 29 anos, Pós-graduação, gestora)

Essa avaliação dirigida ao perfil representado pela Figura 2 é compactuada pela maioria dos informantes moçambicanos. Assim sendo, dos 25 informantes, 11 optaram pela ausência de tratamento ao se dirigir a esse perfil ${ }^{9}, 8$ também se referiram ao perfil com o emprego de "senhora", 4 optaram por "avó/vovó" e os outros 2 por formas como "mãe/mamá". Dessa forma, os informantes associaram a esse perfil a referência a um elemento cultural exógeno e que, portanto, não seria possível estabelecer os mesmos vínculos identitários que se estabeleceria com pessoas associadas ao mesmo universo sócio-cultural.

Igualmente, a fim de se avaliar os valores sociais subjacentes às escolhas linguísticas, foram apresentados aos angolanos dois perfis sociais de profissões amplamente conhecidas no ambiente urbano de Luanda: a quitandeira (Figura 3) e a zungueira (Figura 4).

\footnotetext{
${ }^{8}$ Disponível em: <http://www.flickr.com/photos/31150016@N04/3052963605/>. Acesso em: 12 fev. 2013.

${ }^{9}$ A ausência de tratamento é compreendida como um recurso pragmático significativo.
} 


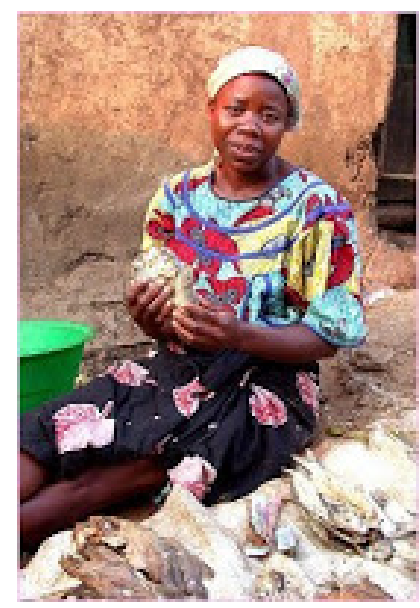

Figura 3. Perfil da amostra angolana ${ }^{10}$

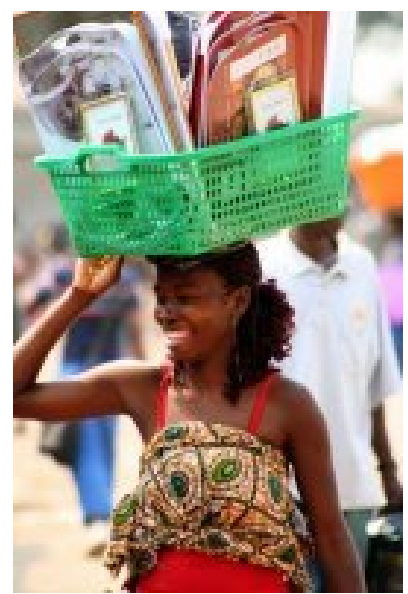

Figura 4. Perfil da amostra angolana ${ }^{11}$

Com um intuito comparativo, à quitandeira seguem os excertos 14 e 15 e à zungueira os excertos 16 e 17:

(14) "Boa tarde, mãe, boa tarde. Mãe, quanto que, quanto é esse, quanto é que custa um monte de peixe? Ou cada peixe, quanto é que custa? E ela vai meter a falar quanto é... ela podes me dizer quanto custa, quanto é que custa quinhentos. Cada peixe é cem kwanzas. Tá, tá bom, mãe. Obrigado. Eu só quis saber o preço. O então, se quiser comprar também posso comprar. É por aí. Trato ela de mãe." (AN, homem, 25 anos, Curso Técnico de Magistério - em andamento, atendente de mesa, bakongo)

(15) "Boa tarde, mãe. Mãe, quero só saber quanto é que custa o, o preço do peixe. Aí depois da resposta dela: obrigado, mãezinha." (AN, homem, 19 anos, Curso Superior em Direito - em andamento, bibliotecário)

(16) “Dona, faz favor. Dona que tá com cesto na cabeça, faz favor. Quanto é que é a bandeja que tá no, que tá no, que tá aí no cesto? Não sei se isto é um tabuleiro ou o quê. Quanto é que é?" (AN, mulher, 46 anos, Ensino Fundamental Completo, arquivista, ngoia)

${ }^{10}$ Disponível em: <http://apresentandoomundo.blogspot.com/2008/08/angola.html $>$. Acesso em: 08 jun. 2013.

${ }^{11}$ Disponível em: <http://asminhasimbambas.blogspot.com/>. Acesso em: 10 jun. 2013. 
(17) “Chama dona. Dona, faz favor. Quanto que é o tabuleiro? Quanto é que tá a vender o tabuleiro, dona? É dona do negócio, né.” (AN, mulher, 28 anos, Curso Superior em Gestão - em andamento, Secretária)

Ao se considerar inicialmente a quitandeira (vendedora de peixe seco, na imagem em questão), dos 25 informantes que participaram da montagem do corpus angolano, 17 referiram tratar o perfil por FTNs como "mãe", "mãezinha", "mamãe", "mamá", 3 escolheram a forma "tia", 3 privilegiaram "senhora", 1 optou por "mana" e outro por "dona", conforme revela o Gráfico 1. No que se refere ao outro perfil em análise, a zungueira (vendedora de tabuleiros/bandejas na imagem em questão), as FTNs escolhidas pelos informantes apresentaram uma diferença substancial em comparação com o perfil anterior: dos 25 informantes, 9 escolheram a forma "dona", 3 favoreceram o uso de "senhora", "tia" foi a opção de outros 3 informantes, 3 optaram por "moça", 3 sentiram-se mais confortáveis com a ausência de FTN, 1 escolheu "amiga", 1 "mana" e, apenas 2 utilizaram as formas "mãe" e "mamá", conforme demonstra o Gráfico 2:

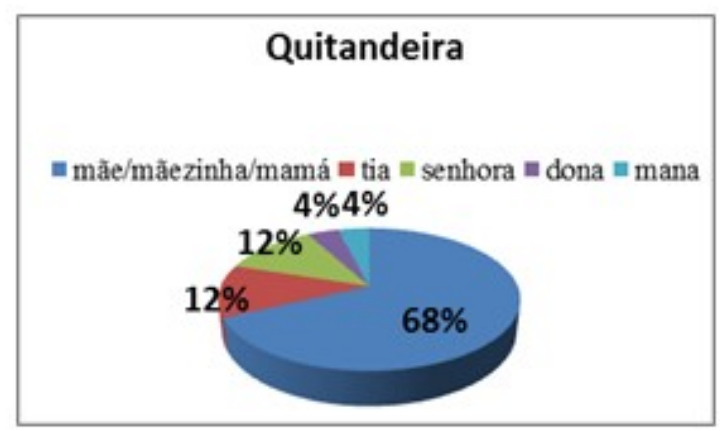

Gráfico 1. FTNs dirigidos à quitandeira

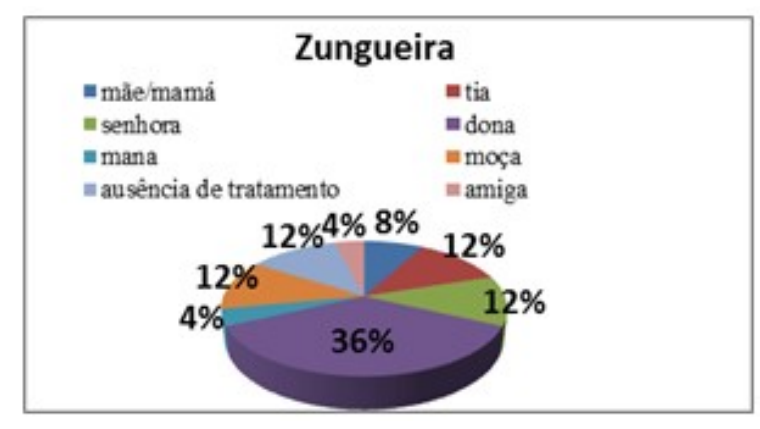

Gráfico 2. FTNs dirigidos à zungueira

Essa diferenciação de tratamentos associados à quitandeira e à zungueira sendo que ao primeiro perfil foram favorecidos os tratamentos familiares - deve-se ao status atribuído a cada uma das profissões. A zungueira, por um lado, é uma profissional relativamente nova na cena urbana de Luanda, uma vez que representa a dificuldade econômica pós Guerra Civil. Nesse sentido, quem se dedica à zunga buscou essa atividade como tentativa de sobrevivência em um país com severas contradições socioeconômicas. Por outro lado, a atividade exercida pela quitandeira remete à tradição cultural angolana, uma vez que é uma profissão desempenhada por sucessivas gerações. Assim sendo, os informantes sentem-se identificados com a quitandeira, por associarem-na com a sua própria ancestralidade. Para expressarem essa pertença, usam FTNs familiares, em especial, "mãe". Entretanto, a reação dos informantes acerca da zungueira - ainda que inconscientemente - é a de não expressar identificação, haja vista que ela é associada a um estatuto sem qualificação, ou seja, ao trabalho informal e ambulante. Em função disso, os informantes evitam chamá-la de "mãe" a fim de não quererem associá-la a sua própria mãe (evitam um tratamento carinhoso, portanto). Assim, as FTNs a ela dirigidas pertencem a um universo semântico mais genérico, exemplificado por "dona". Essa diferenciação pode ser constatada por meio do seguinte depoimento de um informante angolano de 26 anos:

(18) "Exatamente da forma como eu tratei a vendedora de peixe, mas elas têm uma diferença significativa. Eu já não chegaria mãezinha. Eu ia usar dona, por exemplo.

(Ah é?) 
Boa tarde, dona. Desculpe, poderia dizer quanto é que custa o tabuleiro?" (AN, Homem, 26 anos, Curso Superior em Direito - em andamento, estudante, bakongo)

\section{Considerações finais}

Assim sendo, de acordo com o que atesta Tereza Manjate (2010, p. 198-199), o comportamento linguístico afiniza-se com a organização comunitária, de forma que:

Os sentimentos de pertença de uma comunidade constroem os vínculos de solidariedade, de união e de identidade. O poder social tende a converter-se em outras forças estabilizadas e de coesão social se ajustadas ao meio e às condições reais históricas, sociais e ecológicas - de materialização.

Contudo, apesar da existência desse sentimento de identificação social expresso por meio das escolhas das FTNs, ele não ocorreu em todas as situações interlocutivas entre os informantes que participaram dessa pesquisa e os perfis apresentados por meio de imagens fotográficas. Nesse sentido, é possível associar os usos de FTNs familiares a relações simbólicas e fictícias de parentesco, em função do indicativo de carinho e respeito e da expressão de identidade étnica e cultural.

Dessa forma, postula-se que as FTNs familiares expressam essa força intrínseca à organização social, justificando-se, portanto, a associação entre a perspectiva linguística das formas de tratamento e a antropológica das relações parentais. Assim, nas palavras de Radcliffe-Brown (1974, p. 95, grifo nosso):

Quase em toda a parte nas sociedades humanas a primeira experiência que toda a pessoa tem da sociedade ocorre na família parental, o grupo doméstico íntimo constituído por pai, mãe e os filhos. Certas atitudes emocionais desenvolvem-se neste grupo com suficiente força para serem pensadas como 'naturais' no sentido de serem parte da própria natureza humana.

Assim sendo, o sistema de formas de tratamento revela-se como expressivo meio de se observar a relação entre a língua e fatores sociais e históricos. Além disso, evidencia características marcantes das sociedades que utilizam a língua portuguesa como oficial e como veículo que transita por vastos contextos comunicativos da atualidade.

\section{REFERÊNCIAS}

ACEVEDO, A. L. ?De vos, de tu, de usted? Las formas de tratamientos entre los jóvenes guatemaltecos. In: COUTO, L. R.; LOPES, C. R. dos S. As Formas de Tratamento em Português e em Espanhol: variação, mudança e funções conversacionais. Niterói: Editora da UFF, 2011. p. 411-422.

ADICHIE, C. N. Americanah. Tradução de Julia Romeu. São Paulo: Companhia das Letras, 2014.

BALSALOBRE, S. R. G. Fotografias como estratégia metodológica: perscrutando formas de tratamento pronominais brasileiras, moçambicanas e angolanas. LaborHistórico, Rio de Janeiro, 1 (1), p. 132-148, jan./jun. 2015. 
CAUSSE-CATHCART, M. Mi vida, mi amor, mi corazón... formas de tratamiento en el habla de la ciudad de Santiago de Cuba. In: COUTO, L. R.; LOPES, C. R. dos S. As Formas de Tratamento em Português e em Espanhol: variação, mudança e funções conversacionais. Niterói: Editora da UFF, 2011. p. 61-78.

CENTRO DE ESTUDOS E INVESTIGAÇÃO CIENTÍFICA DE ANGOLA (CEIC). Relatório Social de Angola (RSA) 2012. Universidade Católica de Angola (UCAN), Luanda, 2013.

FIRMINO, G. A questão linguística na África pós-colonial: o caso do português e das línguas autóctones em Moçambique. Texto editores: Maputo, 2006.

INSTITUTO NACIONAL DE ESTATÍSTICA. III Recenseamento geral da população e habitação 2007: indicadores sócio-demográficos: Resultados definitivos - Maputo Cidade. Maputo, 2010.

III Recenseamento geral da população e habitação 2007: indicadores sóciodemográficos: Resultados definitivos - Moçambique. Maputo, 2010.

INSTITUTO NACIONAL DE ESTATÍSTICA. Inquérito Integrado sobre o Bem-estar da população (IBEP). Relatório de tabelas. v. II. Luanda, 2011.

KERBRAT-ORECCHIONI, C. Modelos de variação intraculturais e interculturais: as formas de tratamento nominais em francês. In: COUTO, L. R.; LOPES, C. R. dos S. As Formas de Tratamento em Português e em Espanhol: variação, mudança e funções conversacionais. Niterói: Editora da UFF, 2011. p. 19-46.

LÉVI-STRAUSS, C. As estruturas elementares do parentesco. Tradução de Mariano Ferreira. Petrópolis: Vozes, 1982.

A ideologia bipartida dos ameríndios. In: LÉVI-STRAUSS, C. A história de lince. Tradução de Beatriz Perrone-Moisés. São Paulo: Companhia das Letras, 1993.

LOPES, C. R. dos S.; RUMEU, M. C. de Brito. MARCOTULIO, L. L. O tratamento em bilhetes amorosos no início do século XX: do condicionamento estrutural ao sociopragmático. In.: COUTO, L. R.; LOPES, C. R. dos S. As Formas de Tratamento em Português e em Espanhol: variação, mudança e funções conversacionais. Niterói: Editora da UFF, 2011. p. 321-354.

MANJATE, T. M. A. A representação do poder nos provérbios tsonga. 2010. $216 \mathrm{f}$. Tese (Doutorado em Língua e Literatura Românica) - Faculdade de Ciências Sociais e Humanas, Universidade Nova de Lisboa, Lisboa, 2010.

MARIE, A. Filiação, consanguinidade, alianças matrimoniais: parentesco e filiação. In: . Os Domínios do Parentesco (filiação, aliança matrimonial, residência). Tradução de Ana Maria Bessa. Lisboa: Edições 70 (col. Perspectivas do Homem, n. ${ }^{\circ}$ ), 1978.

RADCLIFFE-BROWN, A. R. O estudo dos sistemas de parentesco. In: LARAIA, R. de B. Organização social. Rio de Janeiro: Zahar Editores, 1969.

RADCLIFFE-BROWN, A. R.; FORDE, D. Sistemas politicos africanos de parentesco e casamento. Tradução de Teresa Brandão. Lisboa: Fundação Calouste Gulbenkian, 1974.

SILVA, L. A. da. Cortesia e formas de tratamento. In: PRETI, D. (Org.). Cortesia verbal. São Paulo: Humanitas, 2008. 
O senhor y você. Formas de tratamiento, cortesía y diversidad cultural en portugués. In: COUTO, L. R.; LOPES, C. R. dos S. As Formas de Tratamento em Português e em Espanhol: variação, mudança e funções conversacionais. Niterói: Editora da UFF, 2011. p. 307-320.

TIMBANE, A. A. A variação e a mudança lexical da língua portuguesa em Moçambique. 2013. 318 f. Tese (Doutorado em Linguística e Língua Portuguesa) Faculdade de Ciências e Letras, Universidade Estadual Paulista, Araraquara, 2013.

Recebido em: 14/08/2016

Aprovado em: 01/08/2017 